\title{
Comportamento espectral dos solos, uma relação de cores e mineralogia.
}

Valdinéia Gusmão Silva ${ }^{1}$, Deorgia Tayane Mendes de Souza², Washington de Jesus Sant'anna da Franca Rocha ${ }^{3}$

\author{
${ }^{1 .}$ Estudante de Geografia, UEFS, Feira de Santana-Ba, neiagusmaogeo@gmail.com \\ ${ }^{3}$ Mestre em Geografia- UFBA, Doutoranda em Geociências aplicadas- UnB, Feira de Santana-Ba. deorgiasouza.geo@gmail.com \\ ${ }^{4}$ Geólogo, Professor Adjunto da UEFS, Programa de Pós Graduação em Modelagem em Ciências da Terra e do Ambiente, Feira de Santana- \\ Ba, wrocha@uefs.br
}

Palavras-Chave: Solos; Cartela de Munsell; Espectrorradiometria. INTRODUÇÃO

O solo é considerado um recurso natural básico para a humanidade, uma vez que, a partir dele são extraídas as substâncias necessárias para a manutenção da vida. De acordo com Moreira (2005), o solo pode ser determinado como um corpo natural da superfície terrestre cujas características são resultantes dos efeitos integrados do clima e dos organismos vivos sobre o material de origem, sendo influenciado pelo relevo durante um período de tempo. O estudo pedológico é divido em gênese e morfologia, física, química e mineralogia. Nos atributos morfológicos encontra-se a cor, está se destaca-se por ser uma das feições de mais fácil identificação, sendo utilizada na classificação e interpretação dos solos. As variadas colorações existentes no perfil são muito úteis à identificação e delimitação dos horizontes e, às vezes, ressaltam certas condições de extrema importância. Na definição das cores, a matéria orgânica, óxidos de ferro e demais minerais atuam como principais elementos influenciadores (LEPSCH, 2002).

Neste sentido, a utilização da Cartela de Munsell descrita por Cury et al (1993) como, um sistema de referências de cores do solo, especificando três variáveis que correspondem: o matriz, o valor e o croma e o uso da espectrorradiometria, definida como uma técnica do Sensoriamento Remoto, que consiste na obtenção do comportamento espectral de diferentes alvos. A partir da resposta espectral do solo foi possível identificar a composição mineralógica das amostras estudas. Tais técnicas mostraram-se bastante eficaz, possibilitando a identificação da relação existente entre as cores dos solos e sua composição mineralógica.

Este trabalho tem por objetivo identificar a relação existente entre as cores presentes nos solos e sua composição mineralógica, fazendo uso de duas técnicas de classificação.

\section{METODOLOGIA}

A presente pesquisa teve como objeto de estudo amostras do acervo do Laboratório de Espectrorradiometria (LABESPECTRO), coletados em trabalhos de campo realizados nas cidades de Curaça, Morro do Chapéu e também no Polo de Jeremoabo (Mapa 01).
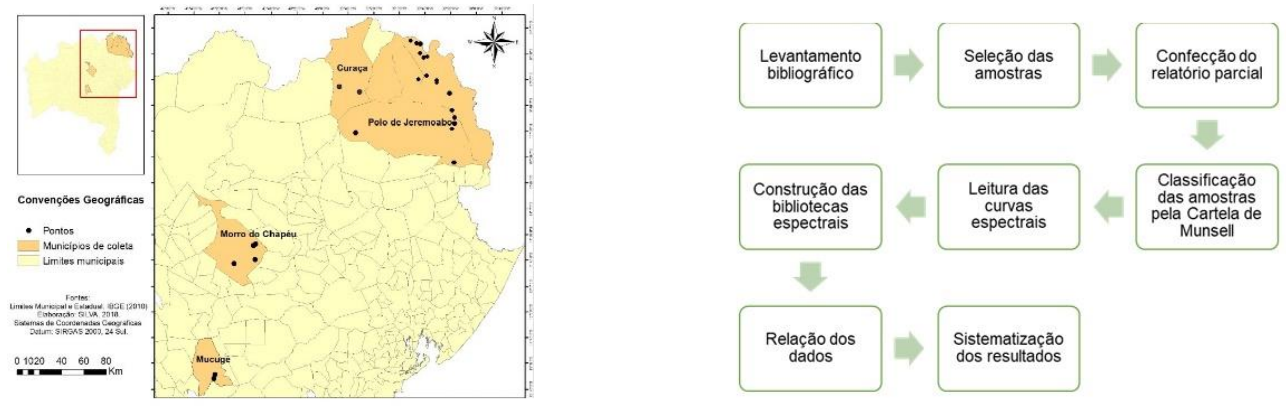

Em um primeiro momento foi realizado uma revisão de bibliografias, que serviu de embasamento para todo desenrolar da pesquisa. Posteriormente foram selecionadas 26 amostras tomando como critério suas diferentes cores, buscando aquelas que apresentassem maiores diferenças. Após a separação das amostras, foi realizado a classificação das mesmas segundo a Cartela de Munsell, observando sua matiz, valor e croma. Na etapa seguinte, foi feita as leituras espectrais daquelas amostras que ainda não possuíam, para isso o material foi antes peneirado e seco em estufa a $45^{\circ} \mathrm{C}$ durante 24 horas. Com as coletas espectrais concluídas, construiu-se as bibliotecas espectrais que possibilitou a identificação mineralógica das amostras em estudo. 
Em seguida foram sistematizados os resultados, identificando a relação existente entre as cores classificadas com a Cartela de Munsell e a composição mineralógica descrita.

\section{RESULTADOS E DISCUSSÕES}

Como critério de organização das bibliotecas espectrais foi utilizada as mensurações alcançadas com a Cartela de Munsell, sendo que as amostras que foram selecionadas pertenciam a ex-bolsistas do LABESPCTRO, o agrupamento das mesmas foi feito de acordo com a classificação da matiz de cada amostra.

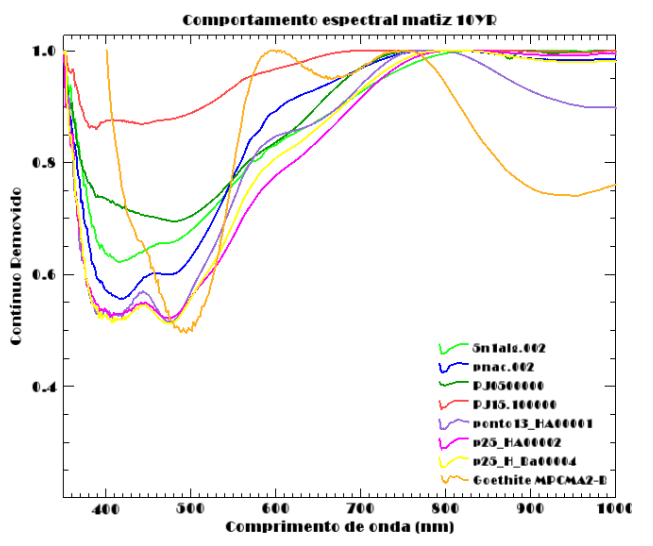

\begin{tabular}{c|c}
\multicolumn{2}{c}{ TABELA01: AMOSTRAS DE MATIZ 10YR } \\
\hline CODIGO DA AMOSTRA & COR \\
5N1ALG & Brown \\
PNAC & Yellowish brown \\
PJ05 & Pale brown \\
PJ15.1 & Liigth gray \\
P13_HA & Yellowish brown \\
P25_HA & Yellowish brown \\
P25_HBA & Yellowish brown
\end{tabular}

De acordo com a Cartela de Munsell todas amostras da biblioteca 01 foram agrupadas na matiz 10YR, ainda segundo a cartela as amostras tiveram seus valores e o cromas variando entre 5/4, 6/3 e 7/2 determinando cores como Yellowish brown, Ligth gray, Pale brown e Brown (tabela 02).

A partir da leitura espectral, foi possível identificar a presença dos óxidos de ferro que constituem à amostra, no intervalo de onda de 400 a $1000 \mathrm{~nm}$. Em todas amostras presentes na biblioteca 01 foram identificados picos de absorção referentes ao mineral goethita, seus picos de absorção foram pontuados nos intervalos de onda entre $385 \mathrm{~nm}$ e $960 \mathrm{~nm}$, a amostra PJ05 assinalou uma suavidade absorção no pico de 877.

Observando as curvas espectrais nota-se que uma maior absorção do ponto 25 em relação as outras curvas, na região do visível, podendo inferir uma maior presença do mineral na sua composição.

Em praticamente todas as amostras da biblioteca é perceptível a interferência da matéria orgânica, devido à redução de refletância na faixa de 600 a $700 \mathrm{~nm}$ mascarando a presença dos óxidos de ferro, no caso a goethita, como afirma Baptista (2006). Está característica é ainda mais acentuada nas amostras PJ05 e PJ15.1.
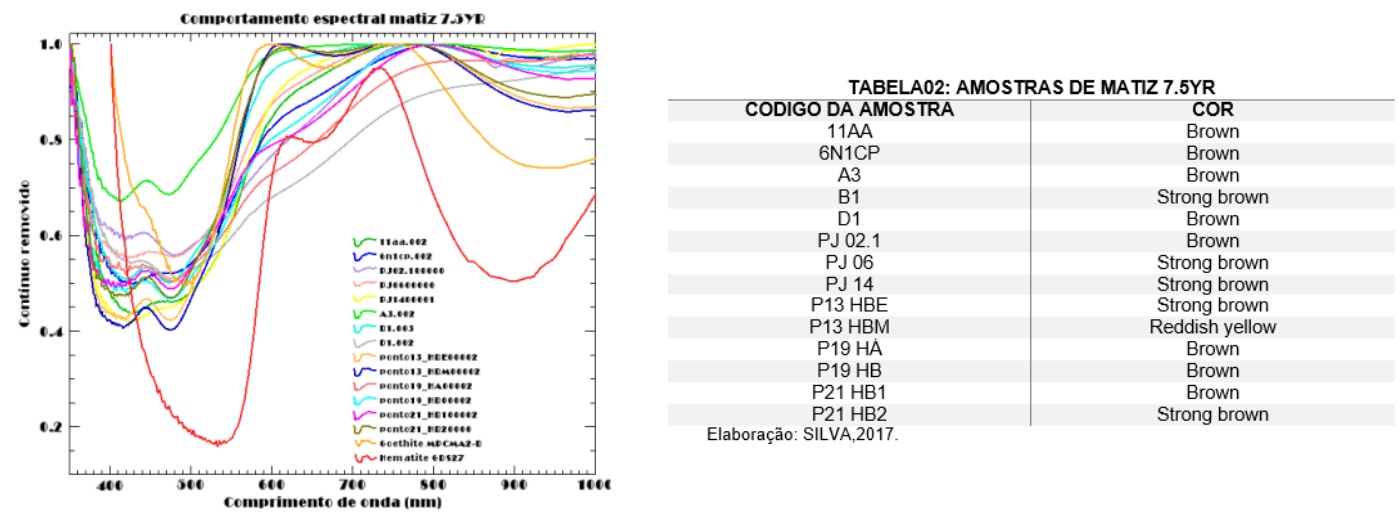

A biblioteca 02 agrupa quatorze amostras classificadas na matiz 7.5YR, seus valores e cromas foram determinados em 4/3;4/4; 4/6;5/3;5/4;5/6;5/8 e 6/8 resultando nas cores Brown, Strong brown e Reddish yellow (tabela 02).

Com as assinaturas espectrais foi possível identificar a assiduidade dos óxidos de ferro goethita e hematita. A goethita foi identificada nas amostras $11 \mathrm{aa}, 6 \mathrm{n} 1 \mathrm{cp}$, em todo ponto 13 e no horizonte B2 do ponto 21 tendo seus picos de absorção entre os intervalos de 430nm e 960nm. Observando as curvas 
destas amostras podemos inferir uma maior presença da goethita no horizonte Bm do ponto 13 devido a sua maior absorção em relação as demais curvas.

Já a hematita mostrou-se mais pontual nas demais amostras, variando os picos de absorção entre o comprimento de onda de $475 \mathrm{~nm}$ a $885 \mathrm{~nm}$, porém pode-se inferir uma maior quantidade do mineral na amostra PJ14 devido sua maior absorção nos intervalos de onda identificados em comparação com as demais curvas. É perceptível também a pontualidade da matéria orgânica no horizonte A do ponto 19, devido à redução de refletância na faixa de 600 a $700 \mathrm{~nm}$.

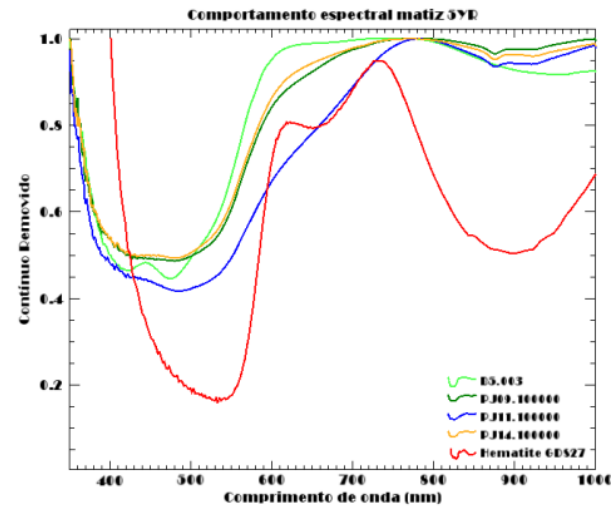

TABELA03: AMOSTRAS DE MATIZ FYR

\begin{tabular}{c|c}
\hline CODIGO DAAMOSTRA & COR \\
B5 & Yellowish red \\
PJ09 & Dark red \\
PJ11.1 & Reddish brown \\
PJ14.1 & Yellowish \\
Elaboração: SILVA,2017. &
\end{tabular}

Na matiz 5YR foram classificadas quatro amostras, que compõem a biblioteca 03. Os valores e cromas destas amostras foram 3/4; 4/4; 4/6 e 5/6 podendo assim classificar as cores em Yellowish red, Dark reddish brown, Reddish brown e Yellowish (tabela 03).

A partir da análise do comportamento espectrais das quatros amostras pode-se perceber a presença da hematita, isto devido aos picos de absorções característicos do mineral, apresentaram-se nos intervalos de $476 \mathrm{~nm}$ a $880 \mathrm{~nm}$.

A amostra B5 apresenta uma maior refletância em relação as demais amostras, como observado no intervalo de 446nm. A assiduidade da matéria orgânica também pode ser observada na amostra PJ11.1 e B5, devido a redução da refletância nos intervalos de onda de 600 a 700nm, porém nota-se uma maior interferência desta nas amostras PJ09 e PJ14

Nota-se que os minerais, a matéria orgânica e a umidade são os principais influenciadores das respostas espectrais obtidas e também na variação de cores dos solos, como observado nas discussões supracitadas.

Quando ocorre a presença de óxidos ferro, como no caso das amostras analisadas, a resposta espectral do mesmo será influenciada, principalmente na região do visível e infravermelho próximo (Formaggio et al., 1996; Galvão et al., 1997).

Baptista (2006), afirma que a goethita $(\mathrm{FeOOH})$ e a hematita $\left(\mathrm{Fe}_{2} \mathrm{O}_{3}\right)$ são os minerais férricos com maior ocorrência encontrados em solos tropicais. Sendo estes resultantes da oxidação do ferro presente como $\mathrm{Fe}^{2+}$ em minerais primários nos processos de formação de solos. Ainda segundo o autor as feições espectrais destes minerais ocorrem principalmente nas faixas espectrais do visível e infravermelho próximo.

A presença da matéria orgânica influência no comportamento espectral dos solos. Sua presença tem o efeito de mascarar algumas feições espectrais, conduzindo a uma linearização da curva espectral (Epiphanio, 1992). Essa característica da matéria orgânica atua principalmente sobre o efeito dos constituintes como o teor de óxidos de ferro, mineralogia, composição granulométrica, além da umidade (DALMOLIN, 2002), tal característica pode ser observada nas bibliotecas espectrais 01 e 02. Segundo Dalmolin (2002), a influência da matéria orgânica vai atuar sobre a forma e o albeno de uma curva espectral ao longo do espectro óptico (400 a 2500nm).

Amostras das bibliotecas 01 e 02 pontuaram a presença da goethita, que segundo Muggler et al (2005), se caracteriza por ser um tipo de óxido de ferro de cor amarela ou amarelo-laranja, sua presença ocorre em solos formados a partir de rochas com baixa concentração de Fe em sua composição, é formada nas primeiras etapas do intemperismo dos minerais primários e se acumula nos horizontes mais próximos à rocha.

A presença da hematita dá a cor vermelha (característica do mineral) e tem um alto poder de pigmentação mesmo quando em baixas concentrações. A presença deste mineral é mais acentuada em solos que 
derivam de rochas ricas em minerais ferromagnesianos e de ocorrência em regiões mais quentes. (MUGGLER, et al., 2005).

Na maioria das amostras selecionadas a relação cores e mineralogia se mostrou precisa, uma vez que a pontualidade da goethita e hematita inferiram praticamente as mesmas cores, podendo identificar também a influência da matéria orgânica na determinação das cores, uma vez que, de acordo com Baptista (2006) a presença da matéria orgânica diminui a refletância nos comprimentos de onda de 600 a $700 \mathrm{~nm}$.

Os comportamentos espectrais pesquisados mostraram similaridade para as amostras que foram classificadas na mesma matiz (segunda a Cartela de Munsell). Dalmolin (2005), discute que as diferentes cores dos óxidos de ferro estão relacionadas à absorção seletiva da luz na região do visível, decorrente da transição dos elétrons na camada orbital. Diferentes feições das curvas espectrais são atribuídas à presença do ferro, demonstrando a goethita e hematita transições eletrônicas no espectro em 530 e 480 nm. A predominância de um ou outro destes minerais relaciona-se a fatores pedoclimáticos (BAPTISTA, 2006).

Tais minerais ocasionam influencias no comportamento espectral do material analisado, garantindo diferentes formas espectrais conforme a sua composição.

\section{CONCLUSÕES}

Analisando os resultados das assinaturas espectrais foram identificados os óxidos de ferro goethita e hematita, os quais em diversas literaturas são apontados como principais responsáveis pela coloração dos solos, assim como a matéria orgânica.

Dentre as vinte e seis amostras analisadas, cinco foram classificadas na cor strong brown; nove na cor brown e uma na cor pale brown esta mostraram-se relacionadas com a presença da matéria orgânica. Outras quatro amostras apresentaram a cor yellowish brown e três amostras apresentaram cada uma a cor reddish yellow, yellowish red e yellowish associadas a presença da goethita e também da matéria orgânica. Estabelecendo uma relação com o mineral hematita e também apresentando a influência da matéria orgânica foram identificadas uma amostra na cor dark red, uma yellowish red e uma reddish brown.

Foi observado também a partir das bibliotecas espectrais, uma similaridade nas assinaturas espectrais que foram classificadas nas cores em tonalidades próximas, inferindo-se que esta característica é decorrente da composição de ambas, que denotam os mesmos tipos de minerais.

Desta forma, mesmo com o grau de subjetividade empregado nas classificações feitas por meio da Cartela de Munsell, quando comparada às respostas obtidas por uma técnica menos subjetiva, os resultados foram coerentes, mostrando assim para ambas as técnicas um desempenho muito eficiente, podendo ser utilizadas nas predições da composição químicas dos solos.

\section{REFERÊNCIAS}

BAPTISTA, G. M. M. SENSORIAMENTO REMOTO: O novo paradigma nos estudos de solos tropicais. / Gustavo Macedo de Mello Baptista. Brasilia: Universa, 2006. 212p.: il.; $21 \mathrm{~cm}$.

DALMOLIM, R.S.D.; GONÇALVES, C.N.; KLAMT, E.; DICK, D.P. Comportamento espectral dos solos se uma topossequência típica da Depressão Central do RS. 2002 (não publicado).

DALMOLIN R. S. D. GONÇALVES, C. N. KLAMT,E. DICK, D. P.Relação entre os constituintes do solo e seu comportamento espectral. Ciência Rural, v.35, n.2, mar-abr, 2005.

EPIPHANIO, J.C.N.; FORMAGGIO, A. R.; VALERIANO, M.M.; OLIVEIRA, J.B. Comportamento espectral de solos do Estado de São Paulo. São José dos Campos, SP, INPE, 1992. 1992. 132p. (INPE-5424-PRP/172).

FONTES, L. E. F.; FONTES, M.P.F. Glossário de Ciências do Solo. UFV, Viçosa, 1992.

FORMAGGIO, A. R.; EPIPHANIO, J. C.N.; VALERIANO, M. M.; OLIVEIRA, J. B. Comportamento espectral (450240 nm) de solos tropicais de São Paulo. Revista Brasileira de Ciências do Solo, Campinas, v.20, p. 467-474, 1996.

GALVÃO, L. S.; VITORELLO, I.; FORMAGGIO, A. R. Relationship of spectral reflectance and color among surface and subsurface horizons of tropical soil profiles. Remote Sensing of Environment. New York, v.61, p. 2433, 1997.

IBGE- INSTITUTO BRASILEIRO DE GEOGRAFIA E ESTATÍSTICA. Manual Técnico de Pedologia, $2^{\mathrm{a}}$ edição. Rio de Janeiro, 2007.

LEPSCH, Igo. Formação e conservação dos solos. São Paulo, SP: Oficina de Textos, 2002. 178p. MUGGLER, C.C., CARDOSO, I. M., FONTES, M. R. M. P. F., ABRAHÃO, W. A. P., CARVALHO, A. F., Conteúdo básico de geologia e pedologia para as disciplinas de SOL 213, SOL 215 e SOL 220. Viçosa-Minas Gerais, 2005. 